Vol. 6(4), pp. 58-66, August 2014

DOI 10.5897/IJ NM2014.0122

Artic le Number: OAC 611746941

ISSN 2141-2456

Copyright (c) 2014

Author(s) retain the copyright of this a ricle

http:// www.academic joumals.org/IJ NM
International Journal of Nursing

and Midwifery

\title{
Socio-economic challenges of parents of children with neurological disorders: A hospital-based study in North West Nigeria
}

\author{
Lawal H. ${ }^{1}$, Anyebe E. E. ${ }^{2 *}$, Obiako O. R. ${ }^{3}$ and Garba S. N. ${ }^{4}$ \\ ${ }^{1}$ Paediatric Unit, Nursing Services Department, ABU Teaching Hospital, Zaria, Nigeria. \\ ${ }^{2}$ Research and Training Unit, School of Nursing, ABU Teaching Hospital, Zaria, Nigeria. \\ ${ }^{3}$ Neurology Unit, Department of Medicine, ABU Teaching Hospital, Zaria, Nigeria. \\ ${ }^{4}$ Department of Nursing Science, Ahmadu Bello University, Zaria, Nigeria.
}

Received 20 January, 2014; Accepted 26 May, 2014

\begin{abstract}
Parents of children with neurological disorders face several socio-economic challenges in nurturing them. Experiences of parents in the study area have not been explored. This descriptive cross-sectional study was designed to investigate socio-economic challenges faced by parents of children with neurological dysfunctions. Paediatric Neurology Outpatient Clinic, Ahmadu Bello University Teaching Hospital Shika, Zaria, Kaduna State, North-West Nigeria, a tertiary health institution was used. A convenience sample of 60 parents was obtained, from whom data were collected through an interviewer-administered structured questionnaire and in-depth interviews on nine of the parents. Sixtyone children were affected (a parent had 2). Cerebral palsy $(50.8 \%)$ and seizure disorders (39.4\%) were the commonest disorders found. A mean age of 5 years was identified. Male (55\%) and the first-born children (44.3\%) were more affected. Perceived causes identified were infection/childhood disease $(65 \%)$, asphyxia (23.3\%), and prolonged labour (18.3\%). The major socio-economic challenges were poor social life and hampered economic status. Parents were themselves deprived of their normal social lives. Parents of children with neurologic problems were found to have faced a lot of socioeconomic challenges that significantly affects the lives of both the affected children and the other siblings. Existing parental poor socio-economic status complicates these challenges. Their economic status and pursuance of family income are hampered, coupled with the high cost of managing the affected children. Social support groups for parents and the affected children should be encouraged by professional bodies, government and non-governmental organizations to enhance social relationships, while ensuring health insurance coverage for these children to reduce economic burden on their parents and enhance maintenance of the healthy status of the other children.
\end{abstract}

Key words: Socio- economic challenges, parental coping, neurological deficit, children.

INTRODUCTION

Most healthy children enjoy normal growth with little need

for specialized health care services. Although care giving

*C orresponding author. E-mail: ejembianyebe@gmail.com or eanyebe@yahoo.com.

Author(s) agree that this article remain permanently open access und er the terms of the Creative Commons Attribution License 4.0 Intemational Lic ense 
is a normal function and desired expectation of every parent; challenges occur when a child experiences functional limitation and long term dependence, because disability in a child affects not only the child but the entire family (Raina et al., 2005; Centre for Child Development, 2007), especially when such children experience difficulties that may require long term special care. Because the brain controls every human function, development of a lesion or lesions in any part of the brain results in a neurological deficit which may hinder the performance of activities and tasks undertaken by that part of the brain. World Health Organisation (WHO) has established that neuro deficits are a major global problem (WHO, 2006).

Neurological disorders are the major causes of functional disability in children (Bajraszewski, 2008), and can result from congenital and hereditary causes, or be environmentally caused. Common neurological disorders in children include: head injuries, trauma to spinal cord, exposure to toxic chemicals and various forms of viral, bacterial, parasitic and fungal infections (Batul, 2011; Raiford, 2013). These disorders commonly cause forms of cerebral palsy, epilepsies and epilepsy syndromes, hydrocephalus, microcephaly, attention deficit, hyperactivity, meningo-encephalitis and autism. These are associated with delays in developmental milestones, muscle rigidity and in-coordination, impairment of speech, hearing and vision. Neurological disorders ultimately lead to learning disability and prolonged dependency (Idro et al., 2010); thus posing enormous psychosocial and socio-economic challenges to parents. This is particularly true of those parents who donot have a good knowledge of the condition and possible ways of addressing the problems of the affected children. WHO recognized the socio-economic challenges of such disorders to all strata of society, but acknowledged the paucity of parental experiences of having children or family members with neuro-disorders (WHO, 2006).

Parents of children with neurological disorders experience socio-economic tiredness and exhaustion (Mungo et al., 2007). The marital relationship may suffer unduly from added stress of blame, guilt and anxiety. A child's disability attacks the fabrics of marriage in different ways and reshapes the organization of the family, creating a fertile ground for conflicts (Vijesh, 2007). Other social challenges are inadequate social support and problems with social life (Ambikile, 2012). The social life may become non-existent and parents may be fearful of rejection by friends/relatives (Vijesh, 2007).

Families of affected children suffer significant financial disadvantages as a result of the need to care for the children (Child Neurology Society, 2012). Financially, more is required to raise a handicapped child, with little prospects of the child earning a living of his or her own. Such children need a multidisciplinary approach and series of investigations such as computerized tomography, magnetic resonance imaging, among others, which poses financial implications on their parents (Batual, 2011). Absence of resources poses a barrier to achieving other outcomes for the parents. Where they exist, family funding services for parents, as opined by Beresford (2007), can be an effective and legitimate way of supporting a disabled child's development and wellbeing. Caplan (2005) identified difficulties in getting insurance coverage for doctor's medication and other treatment as a challenge. Perterson (2011) highlighted that most parents in paid work have to take off time to care for their sick children. Parental income has been positively related to child's outcome. Financial stress, employment loss and overall negative economic impact on families with critically ill child have been demonstrated (Winthrop et al., 2005). A study in California showed that cerebral palsy had the highest life time cost per new case, averaging $\$ 503,000$ in 1992 (Ashwal, 2004).

In Nigeria, the National Health Insurance Scheme Handbook (Act 35 of 1999) states the objectives of the scheme to include ensuring that every Nigerian has access to good health care services, protect families from the financial hardship of huge medical bills, limit the rise in the cost of health care services, ensure equitable distribution of health care costs among different income groups, and maintain a high standard of health care delivery services within the scheme. Other objectives include ensuring efficiency in health care services, improving and harnessing private sector participation in the provision of healthcare services, ensuring adequate distribution of health care facilities within the federation, ensuring equitable patronage of all levels of health care and ensuring the availability of funds to the health sector for improved services. National Health Insurance Scheme (NHIS), as a health care risk spreading mechanism, solves the problem of inequality in the provision of health care services, provides comprehensive health care delivery at affordable cost, covers employees of the formal sectors, self-employed rural communities, the poor and vulnerable groups (Ibiwoye and Adeleke, 2007; Ononokpono, 2008). Abubakar (2007), the NHIS categorizes the users of the scheme into three segments which include a formal sector programme covering public sector (Federal, State and Local Government), armed forces, police and other uniform services, an organized private sector, and students of tertiary institutions. The second classification involves the informal sector which includes rural community, urban self-employed and voluntary participation. The last class is a voluntary group programme which covers permanently challenged persons, the aged, children under five years of age and prison inmates.

Despite the major aim of NHIS being mobilising additional sources of funds to expand and improve access to health care, and if properly implemented, has the potential to improve the health and welfare of the citizens of the country (Adatsi, 2006), it has been 
found that some health professionals perceived that there is dissatisfaction and inconsistencies about the implementation of the scheme and the level of publicity about the scheme (Anyebe et al, in-press).They further stated that, because of this, many healthcare professionals are not registered with the NHIS. The NHIS users are believed to be limited to public sector workers only. In addition to lack of full registration of providers, certain categories of ailments are not covered including neurologic disabilities. The focus here is on the needs of parents of children with neurologic disabilities.

Little is known about the quality of life of parents with developmental diseased children in Nigeria. Donarld et al. (2014) carried out a systematic review of cases of cerebral palsy in the African continent, a researchchallenged environment. This study demonstrated a number of social, economic and psychological burdens of having children with cerebral palsy in the African continent. However, there is insufficient empirical documentation of the needs of the parents of these children in Africa. The present study adds to this literature by specifically studying the needs of parents of neurologically disabled children in the country of Nigeria.

\section{MATERIALS AND METHODS}

\section{Study design and setting}

This study adopted a prospective cross sectional method to explore the experiences of parents of children with neurological disorders attending the Paediatric Neurology Outpatient Clinic of Ahmadu Bello University Teaching Hospital (ABUTH), Shika, Zaria. Parents whose children were not diagnosed as having neurologic problem were excluded. ABUTH, Shika, Zaria is a 700-bed capacity tertiary health institution located in Kaduna State, North Western, Nigeria. It has many specialized outpatient clinics that receive referrals from a population of more than 15 million people spread across 10 states in Northern Nigeria, the Federal Capital, Abuja and adjoining states in Southern Nigeria. The paediatric neurology clinic is one of the specialist clinics.

\section{Study population}

Sixty parents of children with neurological deficits were selected via non-probability, availability sampling. Records at the paediatric neurology outpatient clinic for the previous six months showed an average of 19 of such parents attending the clinic per month. In this prospective study, the investigators estimated an average of 20 parents per month for three months to derive a sample size of 60 .

\section{Instrument and data collection}

The sixty parents (51 mothers, 9 fathers) were interviewed using a 42-item semi-structured questionnaire comprising three (3) sections: (a) socio demographic characteristics of parents and the affected children; (b) perceived causes of neurological dysfunction(s) by parents; (c) socio-economic challenges faced by parents.

The questionnaire was written in English (the official language in Nigeria), but was translated to Hausa (the common language of communication in Northern Nigeria) by a bilingual expert, and then back translated to English by another bilingual expert who was blind to the first translation. Both Hausa and English versions were then pre-tested on 10 parents who were literate and fluent in Hausa language, but semi-literate in English language; in order to remove and correct any ambiguity in the questionnaire, simulate investigator-subject interaction and avoid inter-researcher errors. Thereafter, each of the 60 parents was interviewed either in Hausa or English language depending on their proficiency and choice.

Both qualitative and quantitative data were collected by the first author over a period of three months (September to November, 2012). Parents were consecutively selected and interviewed. The quantitative data were entered into an excel spread sheet and analysed using Statistical Package for Social Science (SPSS; version 17). The qualitative data were recorded with a tape recorder. Those done in Hausa were translated into English, and transcribed. Both quantitative and qualitative data were triangulated to meet research objectives.

\section{Data analysis}

The data obtained were analyzed descriptively using frequency tables, percentages and charts. Chi-square test was used to define relationships between variables. Level of significance was set at $5 \%$, within $95 \%$ confidence interval. The qualitative data were analysed thematically using content analysis.

\section{Ethical clearance}

Permission for the study was obtained from the management of the hospital, while informed consent was obtained from parents after explaining the objectives of the study, the voluntary nature of participation, and the confidentiality of participants' responses.

\section{RESULTS}

\section{The socio demographic characteristics}

\section{Parents}

Table 1 shows that $85.0 \%$ of the parents were mothers, while $15.0 \%$ were fathers. All the parents were married, except one, who was a widow. Majority of the parents were Muslims (85\%) and Hausa/Fulani (71.7\%), respectively. In Nigeria, most Hausa/Fulani are predominantly Muslims. Many respondents (36.7\%) had a tertiary level of education, while $25 \%$ had no form of western education. Majority of the respondents (45.0\%) were self employed, while $25.0 \%$ were full-time housewives. Many (45.0\%) of the respondents could not ascertain how much income they get in a month, however, 20.0\% earned less than N10,000.00 (about $\$ 62.5$ US) per month. Mean income was N57, 666.00 (about \$360 US).

\section{Children}

As indicated in Table 2, of the 61 affected children, $55.7 \%$ were males. The ages of the children range from 
Table 1. Socio demographic characteristics of parents of affected children.

\begin{tabular}{|c|c|c|c|}
\hline Variable & $\begin{array}{c}\text { Mother } \\
(n=51,85 \%)\end{array}$ & $\begin{array}{c}\text { Father } \\
(n=9,15 \%)\end{array}$ & $\begin{array}{c}\text { Total } \\
{[\mathrm{N}=60(100.0 \%)]}\end{array}$ \\
\hline \multicolumn{4}{|l|}{ Marital status } \\
\hline Married & $50(83.3)$ & $9(15)$ & $59(98.3)$ \\
\hline Widow & $1(1.7)$ & $0(0.0)$ & $1(1.7)$ \\
\hline \multicolumn{4}{|l|}{ Tribe } \\
\hline Hausa/Fulani & $38(63.3)$ & $05(8.3)$ & $43(71.6)$ \\
\hline Northern/ Southern minorities & $09(15)$ & $03(5.0)$ & $12(20.0)$ \\
\hline Igbo & $02(3.3)$ & $01(1.7)$ & $3(5.0)$ \\
\hline Yoruba & $02(3.3)$ & $00(0.0)$ & $2(3.3)$ \\
\hline \multicolumn{4}{|l|}{ Religion } \\
\hline Islam & $46(76.7)$ & $05(8.3)$ & $51(85.0)$ \\
\hline Christianity & $05(8.3)$ & $04(6.7)$ & $9(15.0)$ \\
\hline \multicolumn{4}{|l|}{ Educational attainment } \\
\hline None & $13(21.7)$ & $2(3.3)$ & $15(25.0)$ \\
\hline Primary & $5(8.3)$ & $0(0.0)$ & $5(8.3)$ \\
\hline Secondary & $15(25.0)$ & $3(5.0)$ & $18(28.0)$ \\
\hline Tertiary & $18(30.0)$ & $4(6.7)$ & $22(36.7)$ \\
\hline \multicolumn{4}{|l|}{ Occupation } \\
\hline None or full housewife & $15(25.0)$ & $0(0.0)$ & $15(25.0)$ \\
\hline Self employed & $22(36.7)$ & $5(8.3)$ & $27(45.0)$ \\
\hline Government employed & $14(23.3)$ & $4(6.7)$ & $18(30.0)$ \\
\hline \multicolumn{4}{|l|}{ Income per $\mathbf{3 0}$ days in Dollars (Naira) } \\
\hline None/l don't know & $25(41.7)$ & $2(3.3)$ & $27(45.0)$ \\
\hline$<\$ 62.5(10,000.00)$ & $12(20.0)$ & $0(0.0)$ & $12(20.0)$ \\
\hline$\$ 68.75-\$ 125(11,000.00-20,000.00)$ & $2(3.3)$ & $0(0.0)$ & $2(3.3)$ \\
\hline$\$ 131.2-\$ 187.5(21,000.00-30,000.00)$ & $2(3.3)$ & $0(0.0)$ & $2(3.3)$ \\
\hline$\$ 193.75-\$ 250(31,000.00-40,000.00)$ & $0(0.0)$ & $2(3.3)$ & $2(3.3)$ \\
\hline$\$ 256.25(41,000.00)$ and above & $10(16.7)$ & $5(8.3)$ & $15(25.0)$ \\
\hline
\end{tabular}

Table 2. Distribution of age of affected children and their neurological dysfunction by sex.

\begin{tabular}{|c|c|c|c|}
\hline Variable & $\begin{array}{c}\text { Males } \\
(n=34,55.7 \%)\end{array}$ & $\begin{array}{c}\text { Females } \\
(n=27,44.3 \%)\end{array}$ & $\begin{array}{c}\text { Total } \\
(\mathrm{N}=61,100.0 \%)\end{array}$ \\
\hline \multicolumn{4}{|c|}{ *Age of child (years) } \\
\hline $1.0-2.0$ & $8(13.1)$ & $8(13.1)$ & $16(26.2)$ \\
\hline $2.1-4.0$ & $11(18.0)$ & $7(11.5)$ & $18(29.5)$ \\
\hline $4.1-6.0$ & $3(4.9)$ & $5(8.2)$ & $8(13.1)$ \\
\hline$\geq 6.1$ & $12(19.7)$ & $7(11.5)$ & $19(31.1)$ \\
\hline Mean \pm SD & 5.3 years & 4.8 years & 5 years \\
\hline \multicolumn{4}{|c|}{$\chi^{2}=1.911, \mathrm{df}=3$, sig. level $=0.05, \mathrm{CV}=7.815$} \\
\hline \multicolumn{4}{|c|}{ Type of neurologic deficit } \\
\hline Cerebral palsy & $15(24.6)$ & $16(26.2)$ & $31(50.8)$ \\
\hline Seizures & $15(24.6)$ & $9(14.8)$ & $24(39.4)$ \\
\hline ADHD & $2(3.3)$ & $2(3.3)$ & $4(6.6)$ \\
\hline Microencephaly & $2(3.2)$ & $0(0.0)$ & $2(3.2)$ \\
\hline \multicolumn{4}{|c|}{$\chi^{2}=4.084, \mathrm{df}=4$, sig. level $=0.05, \mathrm{CV}=9.488$} \\
\hline
\end{tabular}


Table 3. Social challenges faced by parents of children with neurologic disorders.

\begin{tabular}{lccc}
\hline Social issue & Yes (\%) & No (\%) & Total (\%) \\
\hline Can you travel for days leaving the child at home? & $27(45.0)$ & $33(55.0)$ & $60(100)$ \\
Does the condition of the child allow you to engage in social activities? & $36(60.0)$ & $24(40.0)$ & $60(100)$ \\
Have your friends or relatives avoided you due to this problem? & $06(10.0)$ & $54(90.0)$ & $60(100)$ \\
Do your friends carry the child when they visit you? & $44(73.3)$ & $16(26.7)$ & $60(100)$ \\
\hline
\end{tabular}

Table 4. Helpers/activities carried out.

\begin{tabular}{lcccccc}
\hline Helpers/activities & Bathing & Clothing/Grooming & Feeding & Assist toileting & Carrying/Lifting & Laundry \\
\hline Other siblings & 10 & 08 & 12 & 10 & 09 & 09 \\
Domestic workers & 05 & 06 & 05 & 02 & 04 & 05 \\
& & & & & & \\
Neighbor & 01 & 01 & 01 & 01 & 02 & 01 \\
Spouse & 09 & 09 & 09 & 06 & 08 & 09 \\
Others, e.g family members & 09 & & & & \\
\hline
\end{tabular}

one to above six years, with a mean age of 5 years (a mean age of 4.8 years for females and 5.3 years for males). The common deficits seen were cerebral palsy, seizure disorders and attention-deficit hyperactivity disorder. Nearly a quarter of male children, in the study $(24.6 \%)$ suffer both cerebral palsy and seizure disorders.

\section{Social relationships}

In Table 3, 55\% of parents stated that their own movement was hampered while a good number of them $(40.0 \%)$ missed their social interactions due to the health conditions of their children. Complimenting these findings were narratives from parents. For instance, a woman said: "how can I go out? I do not have anybody to stay with the child". Another mother said, "I don't take her out". "I don't attend social functions because some people gossip about us". Expressing her travail, a mother said, "I don't allow friends to carry her even if they visit me, because she drools saliva. A visitor beat her one day".

However, some parents do have social support as demonstrated in the following narratives from interviews. One woman said, "I leave the child with my neighbour, he likes to stay with her, sometimes I take the child to the school where I teach and keep him with the nanny. They sing and I realize he is happy there." Another woman said: "my mate (the second wife) carries him, bathe him and even clothe him, she has been very supportive."

Most mothers had limited avenues for social interaction, a mother said, "I travel when it is inevitable; most times I have to take care of him and other children". Even when they have to leave home, it is usually few days, a mother said, "I travel, but for one to two days". Another said "at most three days". Table 4 shows the nature of assistance friends and other family members offer. Other siblings and neighbours tend to help more; few are able to hire domestic workers for assistance.

\section{Family relationships}

Buttressing these challenges on family relationships, some parents confessed some difficulty moments. A mother said: "Initially, we quarrelled with my husband, at a point we neglected the child, but later, we learnt to take care of him." Some mothers attested to paternal negligence of the affected child. A mother stated that: "He (her husband) abandoned him (the affected child) and gave more attention to the other children. This makes me unhappy", she lamented. A mother said: "the father has no business with the child; I am all he (the affected child) has." This position was then further explored by the first author by interviewing a few fathers that were available and consented to the interview.

From the In-Depth Interviews (IDIs) conducted, fathers also shared their experiences of the socio-economic travails of caring for neurologically challenged children. Some of these challenges revolve around the foundation of family life and marriage. For instance, a father narrated communication and interaction problems, when he said: "we use to have unnecessary arguments and at times I get bored of everything." Some fathers even expressed their emotions towards the affected children; some reported giving extra care to the affected children. A particular father said: "I like him most. I give extra attention to him."

Some mothers also agreed with the fathers' views on caring for the affected children. A mother simply said: "he is his father's favourite" while another mother said that both the father and herself often "discuss and plan for him (the affected son)." In fact, some other fathers had to quarrel if the affected child is not well cared for. This was how two mothers narrated their experiences: "He quarrels if I don't take care of the child". "He quarrels if I give him 


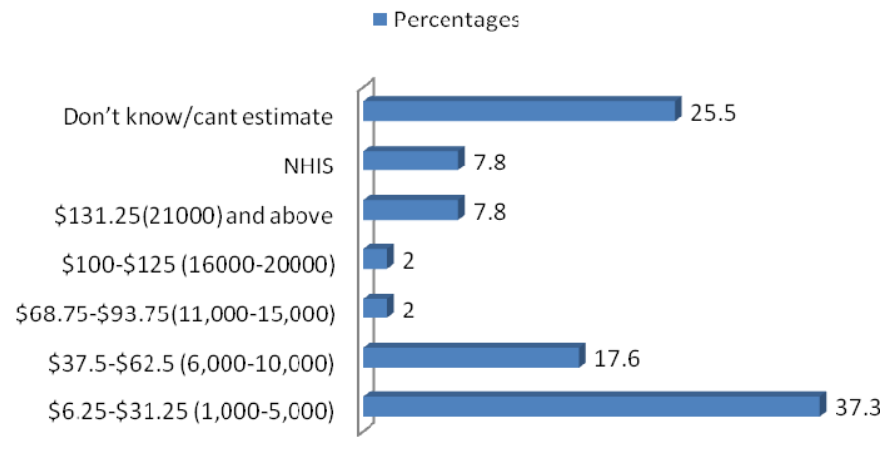

Figure 1. Medical bills and treatment per month.

(the affected child) traditional herbs."

In terms of relationships between parents and the affected child, there is great variation, but in all cases, the child has a profound impact on family dynamics. For example, some other parents described the situation as frustrating, causing parental withdrawal, paternal neglect, reduced attention and unnecessary arguments. These parental decreased attention and neglect manifest in various forms, such as, women complaining of husbands "not sleeping with me" or "no longer entering my room" (indicating absence of sexual relations), as narrated by two mothers. In the study environment, sex is often not openly discussed.

\section{Economic issues and out-of-pocket expenses}

Generally, parents reported that caring for the neurologically affected children is demanding. In further analysis, it was found that some parents $(28 \%)$ could not engage in their economic activities because of the child's health problem. One of the mothers said, "Because the child (with cerebral palsy) can't do anything for himself, I am always attending to his needs". Another mother, while commenting on the same issue, sighed and said:

I have to do everything for him, especially in the morning; he takes plenty of my time. Because he can't talk, I use pampers for him, I have to change it any time he sheet.

For some of the parents whose children suffer seizure disorders, the children were said to be able to take care of themselves. However, at times, the parents helped. A mother said: most times I let her do some things but I have to watch her. A mother said, "because the child cannot talk, and feeding him is difficult, we buy some easy digestible food and diapers all the time".

Some parents had to employ a domestic staff to help. A mother said that she had a worker that watch over her (the affected daughter), and she pays for the services of the staff monthly. The worker employed usually do most physical care; their wages range from N2, 000 to N10, 000 (\$12.5 to \$62.5), per month (Table 4).
Complementing these findings, some parents said that they would not be able to ascertain how much they spend on the children's care.The expenditure on their care included hospital/medical bills and transport fares over long distances to the teaching hospital. They reported that at the onset, they had to carry out a series of investigations and buy different kinds of expensive drugs. For some, the drugs were not readily available. For example, a father lamented: "we spend a lot, we could not get some drugs here, we send to our relations outside Nigeria to help us get the drugs".

For the few $(7.8 \%)$ that enjoy NHIS (Figure 1), nonavailability of most of the prescribed drugs was a problem. One of the parents complained that the: "NHIS don't have some of the drugs, especially the expensive ones." According to NHIS Handbook (1999), the National Health Insurance Scheme was established for the purpose of providing health insurance that entitles insured persons and their dependants (up to four children and a spouse with ailments covered by the scheme) the benefit of prescribed good quality and cost effective health services as set out in this decree. However, the coverage of the few cases is atypical, but covers investigative procedures only. Once diagnoses were established, parents claimed that drugs for treatment are covered by the scheme.

Many parents had to travel for over $300 \mathrm{~km}$ before they could obtain treatment for their children. A parent narrated how they spent days, coming a day or two before their clinic appointment day and go back a day later because of the distance. He said:

We use three days to meet up with his appointment. We leave home on a Sunday, lodge in a hotel around, and see the Doctor on Monday and go back home on Tuesday. We spend a lot of money.

A mother also reported spending up to N100,000.00 (about $\$ 625$ US) at onset. What parents complained as increasing the burden is the non-availability of some investigative procedures recommended; some had to go to other hospitals for some investigations, hence increasing the financial cost. For instance, a mother said: "we had to go to Kano (about $150 \mathrm{~km}$ ) for some scans and come back to continue with this hospital (the study centre)".

Because of the frequency of their visit for physiotherapy, ranging from two to three times a week, some parents employ home based care givers. These additional specialist cares are privately arranged. For example, a mother said: "I employed a private physiotherapist for him."

This economic burden is complicated by inability of some of the parents to attend to their daily businesses. Some parents reported how the care interfered with their business activities. Figure 2 shows the time dedicated to caring for the affected children by parents; some of them 


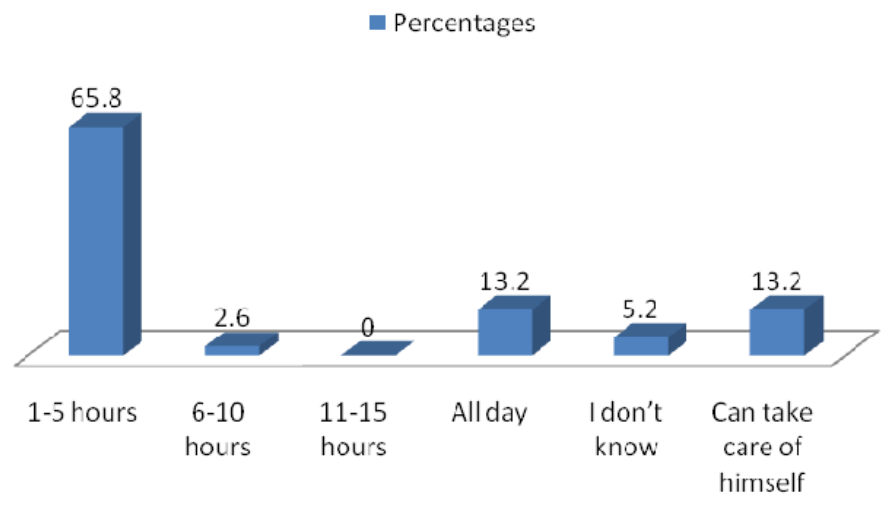

Figure 2. Hours spent to meet child's need per day.

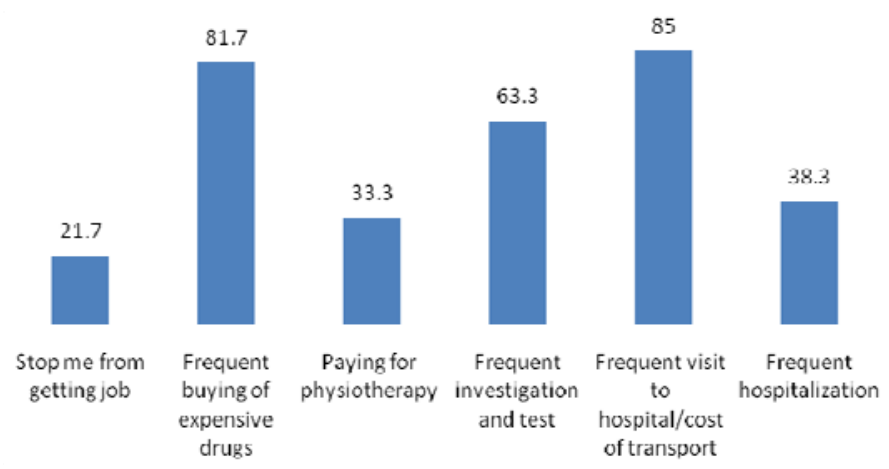

Figure 3. Effect of child's condition on the economic status of the family in percentages.

$(13.2 \%)$ spent the whole day doing that. As shown in Figure 3, frequent visit to hospital (85\%), hospitalization $(38.3 \%)$ and buying of expensive drugs (81.7\%) constitute the major effect of the child's disability on family's economic status. In a narrative, a mother captured this when she said: "I don't open my shop early. I have to take care of him first." The financial implications on unaffected other siblings was also clearly demonstrated when some mothers said that they had to change their other children school from private to Government owned, because they could no longer cope with the payment of the school fees. For others, the feeding and clothing patterns of the family were altered. As a mother regretted, saying: "we don't eat good food like before and we can't buy good cloth for our children," while another lamented how the care of the other children had been compromised because of the increased attention paid to the one with neurologic problem.

\section{DISCUSSION}

\section{Social issues}

The experiences of the affected parents were overwhelm- ing. They expressed the difficulties associated in maintaining social interaction and activities alongside the care of the affected children. Many (55\%) could not travel for days due to the child's state of health, while $40 \%$ could not engage in social activities. This implies a high demand of care with close monitoring of children with neurological challenges. Ambikili (2012) had highlighted that parents of these children face problems with social life. For some $(10 \%)$ in this study, families and close associates appeared unsupportive. Some parents disclosed avoidance of friends and families following the sequelae as $26.7 \%$ claimed that friends/relatives do not carry the affected child even when they visit. Other social problems mentioned by parents were gossiping by people and direct assault of the affected children which may lead to 'stigmatization' and physical injuries. This may make the affected parent prone to depression. Vijesh (2007) reported that the social life may become non-existent and there may be fear of rejection by friends/relatives. Knestrict and Kuchey (2009) described the characteristics of resilient family presented factors that families with children with special needs and disabilities. They pointed out that these parents need social reconstruction of coping with nurturing such children. They found a relationship with the level of socioeconomic status (SES) and such "reconfiguration" in coping with these children socially, psychologically and economically. As can be seen in the present study, the financial burden of parenting children with neurological disabilities negatively affects the socio-economic status of families, compounding the vulnerability the entire family.

\section{Marital challenges}

Marriage as an institution with part of its aim being reproduction can be greatly affected when faced with managing a child with neurological deficit. The effect of these challenges on the marital relationship was also narrated. Some parents reported giving more attention to these children and being more loved than the other children in the narrative. These findings are similar to Vijesh (2007) who reported the situation as affecting the fabrics of marriage and creates a fertile ground for conflicts. Mu'ala et al. (2008) also narrated that mothers were first responsible to child's care. However, paternal involvement in managing such children and good coping and stress control strategies will help keep the marriage.

\section{Economic issues}

The economic challenges appear voluminous and are described by Child Neurology Society (2012) as significant financial disadvantage. Mu'ala et al. (2008) discovered that parent of such children suffer low socioeconomic status, because of the burden of care. Meeting 
the needs/care of the affected children was a heavy weight on the parents shoulder. About $28.3 \%$ of the parents especially mothers had to stop work, hence reducing the family income. Al-Farsi et al. (2013) in their analysis of SES and burden found that caring for children with neuro-psychiatric disorder (ASD) weigh heavily on parents irrespective of SES. In a comparative study with Emerson (2003), it was discovered that mothers of children with intellectual disability experience poor socioeconomic status compared to mothers whose children were not. The demands also affected parents' time. Also, $65.8 \%$ spent between 1 and $5 \mathrm{~h}$ per day to meet the child's need, while some parents had to make themselves available at all times. These findings were also reported by Patterson (2011) who narrated that most parents in paid work had to stop work to care for the affected child. Other associated problems (inability to talk and walk) compounded the task of caring.

Other challenges were centred on the cost of treatment. NHIS coverage was insufficient as discovered in the study. Ihudiebuke (2011) highlighted some factors that hinder the success of NHIS to include the absence of equity in the distribution of health care facilities and access to them, sustainability of government policies and programmes has been a major issue in the country and failure of some insurance schemes might also be a hindrance for the success of the programme.

Medical visit/cost of treatment per month was said to be up to $\$ 131.3$ excluding transportation and other logistics. Rochelle (2005) also described difficulties in getting medical coverage for the affected children. The distance covered to assess medical treatment was an added economic challenge. The treatment difficulties centred on buying expensive drugs, frequent investigations/test (computerized tomography, X-rays, electro encephalogram, etc) and physiotherapy as also highlighted by Baxamusa (2011). Cost of transportation and accommodation bills were other challenges expressed by parents as most of them reported making a long distance trip. The effect reflected on some families as poor feeding pattern, poor clothing and inability to pay for other siblings' school fees.

Winthrop et al. (2005) describe the challenge as having overall negative impact on the families of children who are critically ill. Kneastrict (2009) in his article appears to provide specific interventions for what Emerson (2003) referred to as "combating poverty" and "developing complex models of understanding and intervention". In their specific action plans for families of children with special needs, they suggested a 6-prongs model; namely, making more money, reflecting, observing social norms, positive emotions and effect, resiliency and to live where services are present. Results show that parents' monthly earnings range from meager through poor to no earnings. This poverty level may account for the severity of these challenges. Addition of coverage of neurological disorders to the NHIS would positively affect the economic lives of these vulnerable families.

\section{Conclusion}

This study has shown that parents of children with neurologic problems face many socio-economic challenges. These challenges have significant effects on the lives of both the affected children and other siblings. Poor socio-economic status played an in-enviable role in the lives of the parents. The parents were saddled with meeting responsibilities of their affected children, hence cutting them off from normal social lives. Their economic status and pursuance of family income is also hampered by high cost of management of the affected child, hence making it difficult to maintain optimal socio-economic status and interaction.

\section{RECOMMENDATION}

To avoid suspected stigmatization and possible depression, social groups for parents and the affected children should be instituted by both government and non-governmental organizations to relieve stress and enhance social relationships. In addition, health coverage (NHIS) should be made available for these children to reduce economic burden on their parents and to enhance the healthy status of the other children. Further study is suggested to capture the years of other siblings in relation to the socio-economic challenges and traditional safety nets in affected African families.

\section{Conflict of Interests}

The author(s) have not declared any conflict of interests.

\section{REFERENCES}

Abubakar MS (2007). NHIS as it affect Nursing Practice in Nigeria. A paper presentation at a Conference of Head of Nursing Services, Lokoja, Kogi State.

Adatsi R (2006). Factors affecting enrolment in the NHIS - A study from the Ho Municipality. Unpublished Masters Thesis, University of Ghana, Accra. Available at: http://wiego.org/sites/wiego.org/files/publications/files/alfers-ghananhis-case-study.pdf.

Al-Farsi YM, Waly MI, Al-Sharbati MM, Al-Shafaee M, Al-Farsi O, AlFahdi S, Ouhtit A, Al-Khaduri M, Al-Adawi S (2013). Variation in Socio-Economic Burden for Caring of Children with Autism Spectrum Disorder in Oman: Care Giver Perspective. J. Autism Dev. Disord. 43(5):1214-1221 DOI: 10.1007/s10803-012-16679.Database:Scopus

Ambikile SJ, Outwater A (2012). Child and Adolescent Psychiatry and Mental Health Available at www.capmh.com retrieved on 6/9/2012. Anyebe EE, Bolaji OE, Lawal H, Okeme MI (In-Press). Perceived Effectiveness of the National Health Insurance Scheme Among Health Care Professionals in Zaria, northwest Nigeria. Int. Professional Nurs. J. 
Ashwal S, Russman BS, Blasco PA, Miller G, Sandler A, Shevell M, Stevenson R (2004). Practice Parameter: Diagnostic Assessment of the Child with Cerebral Palsy. American Academy of Neurology. America Neurology. Mar 23; 62(6):851-63

Bajraszewski E, Carne R, Kennedy R, Lanigan A, Ong K, Randall M, Reddihough D, Touzel B (2008). Cerebral Palsy: An Information Guide for Parents, $5^{\text {th }}$ edition. Melbourne: The Royal Children's Hospital.

Batul NB (2011). Neurology Disorders. Available atwww.buzzle.com/articles/neurologicaldisorders/; accessed on 29/5/2013

Beresford B, Rabiee P, Sloper P (2007). Outcomes for Parents with Disabled Children. Society Policy Research Unit, University of Newyork.

Caplan R (2005). Manual for Parents of Children with Epilepsy. Epilepsy Foundation through the General Support of Shile US.

Centre for Child (2007); www.childsupport.in/htmt/adhd/add.html. accessed 29/5/2013

Donarld KA, Samia P, Kakooza-Mwesige A, Bearden D (2014). Peadiatric Cerebral Palsy inAfrican: a Systematic Review. In Seminars in Paediatrics Neurology. WB Saunders, p.1-2

Emerson E (2003). Mothers of children and adolescents with intellectual disability: social and economic situation, mental health status, and self -assessed social and psychological impact of the child's difficulties. J. Intellect. Disabil. Res. 47 (part 4/5):385-399. (journal article-research, tables/charts) ISSN:0964-2633 PMID: 12787168,Database: CINAHL Plus

Idro R, Kakooza-Mwesige A, Balyejjussa S, Mirembe G, Mugasha C, Tugumisirize J, Byarugaba J (2010). Severe Neurological Sequelae and Behaviour Problems after Cerebral Malaria in Ugandan child. BMC Research Notes, 3:104. Available at: http://www.biomed central.com

Ihudiebuke, Splendor, Chikaodin (2011). National Health Insurance Scheme in Nigeria: Problem and Prospects: Nurs. Extra, Edition 3, 3:16-18,36

Kneastrict T (2009). Welcome to Holland: helping families develop resiliency. Exceptional parent, 39(4):36-39. (journal article-pictorial) ISSN: 0046-9157, Database: CINAHL Plus

Knestrict T, Kuchey D (2009). Welcome to Holland: Characteristics of resilient families raising children with severe disabilities. J. Family Studies. December 2009, 15(3):227-244 DOI:

10.5172/jf.15.3.227, Database: Scopus

Mu'ala AE, Abas AR, Shawam SS, (2008). Psychological Burden of a Child with Cerebral Palsy upon Care Givers in Erbil Governorate, The Iraqi post graduate med. J. 7(2)

Mungo D, Ruta L, Genitori DV, Mazzone L (2007). Impairment of quality of life in parents of children and adolescents with pervasive developmental disorder.Health and Quality of Life Outcomes. Available at; www.hqlo.com/content.

National Health Insurance Scheme Handbook (1999).National Health Insurance Scheme Decree № 35 of 1999 Laws of the Federation of Nigeria pp. 4-13.
Paterson L (2011). Parenting: Different kinds of parenting, Te-Ara- the encyclopedia of New Zealand:Ministry of Culture and Heritage, NZ Government.

Raiford T (2013). GlobalPost - Parents of Children with Cerebral Palsy; International New, Available http://everydaylife.globalpost.com/parent-children-cerebral-palsy4578.html; accessed on 29/5/2013

Raina P, O'Donnell M, Rosenbaum P, Brehaut J, Walter S, Russell D, Swinton M, Zhu B, Wood E (2005). The Health and Wellbeing of Care Givers of Children with Cerebral Palsy Available http://www.ncbi.nlm.nih.gov/pubmed/15930188

Vijesh PV, Sukumaran PS (2007). Stress among Mothers of Children with Cerebral Palsy Attending Special Schools, Asian Pacific Disability Rehabilitation J. 18(1).

Winthrop AL, Brasel KJ, Stahovic L, Paulson J, Schneeberger B, Kuhn EM (2005). Quality of life and functional outcome after pediatric trauma. J. Trauma 58(3):468-473. discussion 473464. 